\section{Tastevin: uma história da etnografia indígena}

Por Heloisa Maria Bertol Domingues

Doutora em História Social pela Universidade de São Paulo. Pesquisadora Titular do Museu de Astronomia e Ciências Afins, Ministério da Ciência e Tecnologia

(heloisa@mast.br)

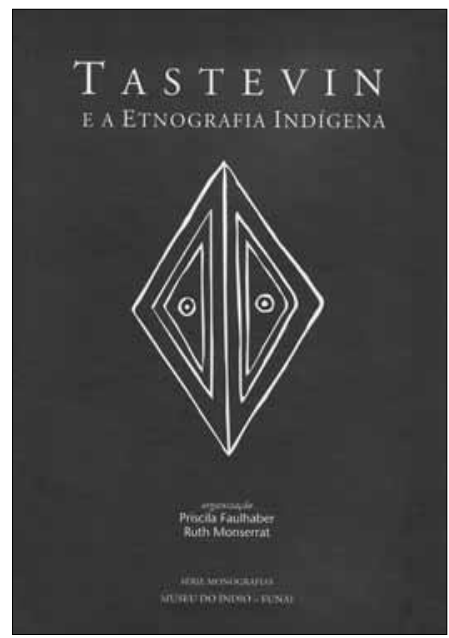

FAULHABER, Priscila; MONSERRAT, Ruth (Orgs.).

Tastevin e a etnografia indígena: coletânea de traduções de textos produzidos em Tefé (AM). Rio de Janeiro: Museu do Índio/FUNAI, 2008. Série Monografias. 213 p. ISBN 978-85-85986-14-8

O livro organizado por Priscila Faulhaber e Ruth Monserrat, intitulado "Tastevin e a Etnografia Indígena", traz uma dupla contribuição para as ciências. Sendo, em si, um trabalho etnológico, é um instrumento importante para suporte a estudos etnológicos da Amazônia. Mas, sobretudo, é um magnífico trabalho de preservação da memória cientííca. Ou seja, esse livro, lançado no final de 2008 pelo Museu do Índio, representa, ao mesmo tempo, uma contribuição à prática da etnologia e à história das ciências.

O livro é composto de traduções de textos produzidos pelo Pe. Constant Tastevin durante sua missão religiosa junto aos índios em Tefé, Amazonas, onde residiu entre 1905 e 1926, a serviço da Congregação do Espírito Santo. Contudo, não se tratam de meras traduções (o que não teria diminuído o valor do livro, pois estão bem feitas, constituindo um significativo trabalho de mutirão entre colegas). Tratam-se de textos com profundas reflexões sobre a cultura indígena da Amazônia, daqueles anos do início do século $X X$. Enriquecendo as traduções, as organizadoras realizaram um trabalho paralelo de etnologia, atualizando termos e expressões e definindo categorias botânicas, geográicas, químicas, técnicas de trabalho e instrumentos de uso cotidiano, característicos da região. As notas são uma segunda fonte importante de informação e se equivalem a um dicionário antropológico, transformando-se, também, num trabalho de tradução cultural, como consideraram o de Tastevin. Nesse sentido, o livro traz uma contribuição, pode-se dizer, didática a todos os interessados em estudos da cultura, bem como aos leigos, pois permite a todos penetrar numa linguagem muito típica.

Não resta dúvida de que "Tastevin e a Etnografia Indígena" atinge o objetivo de contribuir com todos aqueles que se dedicam ao campo da história indígena, ao indigenismo e aos movimentos indígenas. Ele serve, ainda, àqueles que estudam a história do meio ambiente, da exploração dos recursos naturais e da cultura das sociedades de um modo geral. Mostra o quanto as produções do passado continham em idéias e em preocupações, que ainda hoje estão no centro das atenções. Por outro lado, o livro corrobora a importância de se preservar a memória, reproduzindo-a.

Os textos de Pe. Tastevin, um fazer etnografia, são o resultado do trabalho de campo do etnógrafo. Eles retratam a cultura amazônica nas observações sobre o diaa-dia, sobre os modos de vida dos índios: como moravam, o que comiam, como preparavam e usavam instrumentos de uso nas casas, na pesca, na caça, na sua defesa, o que valorizavam na natureza. $O$ livro mostra a vida da sociedade e a sua relativização às potencialidades do meio.

O contexto social e político no qual se desenrolou o trabalho de Tastevin na Amazônia foi o que antecedeu e procedeu à Primeira Guerra Mundial. Foi, também, o da expansão das potências econômicas européias e dos Estados Unidos sobre as regiões tropicais. A Amazônia ainda vivia o auge do movimento de exploração da borracha e de sua exportação. Tastevin pôde, assim, estudar o contato entre as diferentes culturas em consequência do movimento de entrada dos seringueiros, vindos do 
Nordeste do Brasil. Naquela conjuntura, a Amazônia se descortinava como um lugar a explorar e viver. $\bigcirc$ grande volume do comércio dos produtos florestais levou a região a estruturar-se economicamente nas primeiras décadas do século $X X$, com o estabelecimento de bancos comerciais, de companhias estrangeiras de comércio e de colonização e com as concessões de terras a estrangeiros (Reis, 1972, p. 157-173). Os naturalistas e os geógrafos que percorreram a Amazônia para inventariá-la, e também os missionários, serviam, ao mesmo tempo, aos interesses mercantis e políticos de suas pátrias.

Priscila Faulhaber e Ruth Monserrat, coerentes com o objetivo do livro, enfatizaram o aspecto etnológico que apresentava Tastevin, porém, tiveram o cuidado de não ignorar que aquele trabalho, na Amazônia, estava associado à política de expansão colonialista do Estado francês. Conforme mencionado na Introdução do livro, Tastevin, com seu trabalho de etnólogo, tinha a intenção de quebrar o que ele chamou de monopólio alemão do conhecimento científico sobre os índios da Amazônia, pois, naquele momento, predominavam os estudos de Theodor KochGrünberg e Paul Ehrenreich. Também, naquelas primeiras décadas do século $X X$, empresas estrangeiras passaram a pleitear concessões de exploração para se estabelecer em terras da Amazônia. Tastevin, fazendo etnologia, pretendia recuperar a tradição francesa de estudos científicos, que ele considerava exemplares, como os de Jules Crevaux, Conde de Castelnau (François Louis de la Porte), Paul Marcoy e Alcide D'Orbigny, realizados na região.

Chama a atenção, nos escritos de Tastevin, a preocupação em fazer um reconhecimento minucioso de cada lugar, marcando tanto as diferenças físicas do meio, quanto as diferenças entre as práticas culturais. Ao tratar dos fazeres dos índios em cada lugar, observou a diferença na feitura de utensílios domésticos, das construções, do que comiam, como se abrigavam. Tastevin, num esmerado trabalho geográfico, enumerou os recursos naturais explorados e mostrou o conhecimento desenvolvido sobre eles, pelos índios, evidenciando o processo de sua transformação em objetos de uso. Salientou, assim, os conhecimentos técnicos de construção das casas, dos meios de transporte, de armas, de utensílios domésticos etc. Descreveu os conhecimentos químicos que haviam desenvolvido para o preparo de alimentos, de medicamentos e de venenos. Não havia conhecimento e prática em separado, havia uma prática dos conhecimentos, uma simultaneidade entre o pensar e o fazer, como bem demonstra Tastevin quando descreve, por exemplo, o preparo e o uso da mandioca (ver capítulo "Preparação e uso da Mandioca na região do Médio Amazonas e de seus afluentes", p. 111-117). Um trabalho que as mulheres realizavam cantando, num sentido de comunidade. Em descrições como essa se percebe o trabalho meticuloso do etnógrafo que foi Tastevin.

Do ponto de vista dos estudos sobre o homem, Tastevin se alinha àqueles que já não o viam como simples objetos da natureza, visão que havia predominado no século XIX e que continuava predominando nos estudos antropológicos. A etnologia que então valorizava a cultura dos índios, ao lado da geografia humana que também se afirmava enquanto ciência, foi decisiva para transformar o homem em objeto das ciências sociais. Ou seja, era a época em que se iniciava historicamente um corte nas ciências naturais, introduzindo-se as ciências sociais. O trabalho de Tastevin situa-se nessa franja do novo campo de pesquisa científica.

Tastevin traz, também, uma preocupação ainda atual, que é a questão da preservação da natureza, contra o desperdício e a despreocupação com a fecundidade biológica dos animais. Cita o problema da iminência da extinção das tartarugas em consequência da destruição dos ovos, usados para extrair um óleo comercializado há mais de século. Ele criticou o fato dos índios nunca terem se preocupado em criar animais, embora fossem hábeis em domar todas as espécies: "da anta ao esquilo, da garça ao beija-flor". "(...) Ele [o índio] utiliza a abundância com que Deus o mima sem pensar em prevenir a escassez". Não havia palavra no vocabulário para exprimir a fecundidade, atentou sua acurada observação.

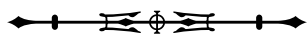


Havia, porém, uma particularidade da cultura dos índios da Amazônia que chamou ainda mais a atenção de Tastevin: o casamento; feito sem convenções oficiais e desfeito sem traumas tantas vezes quantas quisessem, o que, na interpretação do etnólogo, causava frieza nas relações, tanto entre o casal, quanto nas relações paternas e maternas. Não havia manifestação de amor filial. Para Tastevin, essas relações contribuiam para o "perfeito estado de comunismo" em que viviam. Os únicos pertences dos indivíduos eram as armas. A roça de mandioca, a casa, as canoas, tudo era comunitário. Manifestava uma crítica, embutindo uma posição política.

Nada, na cultura, fugiu à percepção daquele etnógrafo. Assim, o livro "Tastevin e a Etnografia Indígena" atualiza as relações sociais, as questões do clima, da exploração da floresta e dos rios, num momento em que as mudanças climáticas ocupam a mente dos políticos e da sociedade em geral, e em que a situação dos povos amazônicos, ribeirinhos e da floresta, tem o foco do mundo voltado sobre eles, aguçado pelo interesse na biodiversidade. Esse livro torna-se, assim, leitura obrigatória de todos quantos desejam aprofundar o conhecimento sobre os índios, os lugares onde habitam e a Amazônia.

\section{REFERÊNCIAS}

REIS, Arthur Cezar Ferreira. A Amazônia e a cobiça internacional. 4 ed. Rio de Janeiro: Companhia Editora Americana, 1972. 